\title{
Violence in persons with and without psychosis in the Czech Republic: risk and protective factors
}

This article was published in the following Dove Press journal:

Neuropsychiatric Disease and Treatment

\author{
Martin Černý, ${ }^{1,2}$ Sheilagh \\ Hodgins, ${ }^{3}$ Radmila Kučíková, ${ }^{2,4}$ \\ Ladislav Kážmér, ${ }^{5}$ Alena \\ Lambertová,' Alexander \\ Nawka,' Lucie Nawková,' Anna \\ Parzelka,' Jiří Raboch,' Petr \\ Bob,' Jan Vevera ${ }^{1,6-8}$ \\ 'Department of Psychiatry, First Faculty \\ of Medicine, Charles University in Prague \\ and General University Hospital in Prague, \\ Prague, Czech Republic; ${ }^{2}$ Department of \\ Psychiatry, Teaching Hospital Královské \\ Vinohrady, Prague, Czech Republic; \\ ${ }^{3}$ Institut Universitaire en Santé Mentale \\ de Montréal, Département de Psychiatrie, \\ Université de Montréal, Montréal, Quebec, \\ Canada; ${ }^{4}$ Psychiatric Hospital Bohnice, \\ Prague, Czech Republic; ${ }^{5}$ Center for \\ Epidemiological and Clinical Research in \\ Addictions, National Institute of Mental \\ Health, Klecany, Czech Republic; ${ }^{6} 7$ th Field \\ Hospital, Czech Armed Forces, Hradec \\ Králové, Czech Republic; ${ }^{7}$ Department of \\ Psychiatry, Faculty of Medicine, University \\ Hospital in Pilsen, Charles University, \\ Prague, Czech Republic; ${ }^{8}$ Department \\ of Psychiatry, Institute for Postgraduate \\ Medical Education Prague, Prague, \\ Czech Republic
}

Correspondence: Jan Vevera

Department of Psychiatry, Faculty of Medicine, University Hospital in Pilsen, Charles

University, Alej Svobody 80, 30460 Pilsen,

Czech Republic

Tel +42037 710 3100

Fax +420377103956

Email veverajan@gmail.com
Purpose: To prevent violence among persons with psychosis, further knowledge of the correlates and risk factors is needed. These risk factors may vary by nation.

Patients and methods: This study examined factors associated with violent assaults in 158 patients with psychosis and in a matched control sample of 158 adults without psychosis in the Czech Republic. Participants completed interviews and questionnaires to confirm diagnoses, report on aggressive behavior, current and past victimization, and substance use. Additional information was collected from collateral informants and clinical files. Multiple regression analyses were conducted to identify factors that were independently associated with committing an assault in past 6 months.

Results: The presence of a psychotic disorder was associated with an increased risk of assaults $(\mathrm{OR}=3.80 ; 95 \% \mathrm{CI} 2.060-7.014)$. Additional risk factors in persons with and without psychosis included recent physical victimization ( $\mathrm{OR}=7.09$; 95\% CI 3.922-12.819), childhood maltreatment $(\mathrm{OR}=3.15$; 95\% CI 1.877-5.271), the level of drug use (OR $=1.13 ; 95 \%$ CI $1.063-1.197)$, and the level of alcohol use (OR $=1.04 ; 95 \%$ CI 1.000-1.084). Increasing age (OR $=0.96 ; 95 \%$ CI $0.942-0.978)$ and employment ( $\mathrm{OR}=0.30 ; 95 \%$ CI $0.166-0.540)$ were protective factors. Except for drug use, which appeared to have greater effect on violence in the group without psychosis, there were no major differences between patients and controls in these risk and protective factors. To our knowledge, this is the first published comparison of assault predictors between schizophrenia patients and matched controls.

Conclusion: Recent physical victimization was the strongest predictor of assaults. Our findings are consistent with the emerging empirical evidence pointing to the very important role of victimization in eliciting violent behavior by the victims. Some current prediction instruments may underestimate the risk of violent behavior as they take little account of current victimization. Although psychosis per se elevates the risk of violence, other risk and protective factors for violence in persons with psychosis and comparison group are largely similar.

Keywords: schizophrenia, psychosis, violence, victimization, risk

\section{Introduction}

Studies conducted in different countries have shown that persons with psychotic disorders are at increased risk, as compared to the general population, to engage in violent crime, including assaults. ${ }^{1,2}$ A recent meta-analysis examined a large number of risk factors for violence in the mentally ill. ${ }^{3}$ These included male gender, lower age, lower educational attainment, history of childhood maltreatment and adult violent victimization, unemployment, unmarried status, recent alcohol and drug misuse, recent violent behavior, and current psychopathology, particularly positive psychotic symptoms. The risk factors for violence in released prisoners ${ }^{4}$ are similar to those observed 
in the mentally ill. However, we are not aware of any published formal comparison of risk factors in persons with and without mental illness.

While ORs for violent crimes (such as assaults) are similar across countries, the proportions of persons with psychosis who engage in assaultive behavior differ. ${ }^{5}$ Consequently, it may be that the factors associated with assaultive behavior by persons with psychosis also vary across countries. Rates of crime differ from one nation to another, as do the proportions of persons experiencing factors associated with an increased risk of violence, such as using drugs, experiencing physical victimization, ${ }^{1,6}$ physical and sexual abuse in childhood, and posttraumatic stress disorder (PTSD). Hence, there is an importance of comparing violence and correlates of violence, among persons with and without psychotic disorders within the same culture.

Most of the risk factors have been known for a long time, ${ }^{7}$ but empirical evidence for the importance of violent victimization of patients with psychosis as a risk factor for violent behavior has been emerging only recently. ${ }^{8-12}$ Furthermore, returning veterans with PTSD frequently develop aggressive behavior, and $-30 \%$ of schizophrenia patients develop PTSD as a result of victimization and other traumatic experiences. ${ }^{13,14}$ Thus, PTSD in schizophrenia is a potential risk factor for violence.

In this study, in Czech Republic, we aimed to compare the prevalence of assaults by persons with and without psychotic disorders and to investigate risk factors for assaultive behavior. Specifically, we planned to test whether demographic data, childhood maltreatment, recent victimization, recent alcohol and drug misuse, and PTSD were independent risk factors for violence in persons with and without psychosis. Separate assessments of predictors in these two groups aimed to facilitate group comparisons. We also aimed to examine psychopathology concurrent with violent assaults.

\section{Patients and methods}

\section{Participants}

\section{Group with psychotic disorders}

All patients older than 18 years hospitalized for $\geq 3$ days in a psychiatric hospital from April 2008 to November 2009 with the Tenth Revision of the International Classification of Diseases (ICD-10) diagnoses of schizophrenia, delusional disorder, acute polymorphic psychotic disorder, and schizoaffective disorder were invited to participate in the study if their treating psychiatrist judged that they were competent to consent to participate. Of the patients approached, $92.4 \%$ agreed to participate.

\section{Collateral informants of participants with psychotic} disorders

Almost all (94.3\%) of the participants with psychosis identified someone who could report on their behavior. Most often, collateral informants were family members $(73.8 \%)$, friends (6.0\%), or professionals $(20.1 \%)$.

\section{Comparison group}

The comparison group consisted of acute outpatients of the Department of Stomatology from the same University Hospital and people living in the same low economic accommodation (hostels) in which the patients resided after hospital discharge. The Department of Stomatology was chosen because similarity of residence implied similarity of socioeconomic status (SES). The comparison group was matched according to age, gender, and level of education, which was used as a proxy for SES. We used those proxies of SES since no validated questionnaire for the assessment of SES was available in Czech language. The control group was evaluated by identical scales without The MacArthur Community Violence Interview for collateral; data from collaterals were not required.

Participants were consecutively recruited from individuals consulting an acute dental clinic in the same city in neighborhood of psychiatric hospital during 21 days in September and October 2009. Almost all, 96.2\%, of those invited to participate in the study agreed. A total of 242 individuals, aged $\geq 18$ years, were eligible for the study and agreed to participate. However, among the 242 , there were not enough males with only elementary school education to match the psychotic disorder group. Therefore, 19 participants were recruited from a hostel for low-income persons; these participants were compensated with 100 Czech crowns for their participation. All the comparison group participants completed a diagnostic interview to ensure that none had a history or current psychotic disorder. From among the 261 individuals recruited (242+19), 93 males and 65 females who matched the males and females with psychosis on age and level of education were included in the comparison group.

\section{Procedure}

After having the study explained, participants signed consent forms and then completed questionnaires and an interview with a psychiatrist to diagnose mental disorders and to assess violence, current and past victimization. Reported incidents were reviewed in order to classify their severity as moderate or serious. 


\section{Instruments}

\section{Diagnoses}

The Czech translation of Mini International Neuropsychiatric Interview (MINI) ${ }^{15}$ was used to assess mental disorders among all participants. Interrater meeting assessed high interrater reliability as indicated by a kappa value of 0.960 for the total score.

\section{PTSD}

The Czech translation ${ }^{16}$ of PTSD module of the Structured Clinical Interview for $D S M-I V^{17}$ was administered by psychiatrists in order to identify lifetime prevalence of PTSD. The Czech version of the interview is not validated.

\section{Substance abuse}

Together with MINI, two self-reported validated questionnaires, the Alcohol Use Disorders Identification Test $(A U D I T)^{18}$ and the Drug Use Disorders Identification Test (DUDIT),${ }^{19}$ were used to assess substance use. Hazardous and harmful patterns of alcohol consumption were assessed using validated Czech version of the AUDIT screening questionnaire, where hazardous drinking was defined as AUDIT score of $\geq 8$, harmful drinking as an AUDIT score of $\geq 16$, and problem drinking (possible dependence) as AUDIT score $\geq 20$. $^{20}$

Harmful illicit drug use was defined as a DUDIT score of 6 among men and 2 among women, and illicit drug dependence as a DUDIT score of 25 for men and women. ${ }^{19}$ Before the use for the study, DUDIT was subject of translation and back translation, and basic psychometric properties were validated with satisfactory results (Cronbach's $\alpha 0.888$, inter-item correlation 0.498 ).

\section{The MacArthur Community Violence Interview}

The MacArthur Community Violence Interview ${ }^{21}$ described $^{-}$ violence in terms of the type of act committed, its target, and its location. Patients and collateral informants were asked whether the patient had engaged in several categories of aggressive behavior (eg, kicking, slapping, punching, threatening with weapon) in the past 6 months. If a positive response was given, the patient or informant was asked to list the number of times the behavior occurred. Detailed information was obtained about each act, including the target, location, and presence of psychotic symptoms (22 items and nine multiple choice answers in description part). Acts reported by researchers were reviewed by the first author to obtain a single reconciled report of violence. In case of multiple acts of one patient, only the most serious incident was coded.

The interview was used to measure violent behavior at two levels of severity: moderate violence, corresponding to simple assault without injury or weapon use; and serious violence, corresponding to any assault using a lethal weapon or resulting in injury, any threat with a lethal weapon in hand, or any sexual assault. ${ }^{22}$

Victimization of assaultive behavior was defined as moderate when the victim's injuries did not require medical care and no weapon was involved and severe when the victim required medical intervention, or a weapon or sexual attack was involved.

Reports of assaults by patients with psychosis and their collaterals concurred for $79.7 \%$ of any assaults. Reports of victimization concurred for $75.3 \%$ of the incidents of victimization reported by patients with psychosis and collateral. The presence of positive psychotic symptoms at the time of an assault referred by patients or collaterals were retrospectively rated as none, possible, or present and coded for analyses as present or absent (those possible or none).

Before the study, the interview was translated and back translated. Basic psychometric properties were validated with satisfactory results (Cronbach's $\alpha$ 0.721, inter-item correlation 0.171 ). Inter-rater reliability was high as indicated by an intraclass correlation coefficient $=0.94$ (CI 0.80-0.97).

Patient and control groups were evaluated by identical scales except that the controls were not administered the MacArthur Community Violence Interview for collateral information.

\section{Childhood maltreatment}

The Childhood Experience of Care and Abuse questionnaire (CECA.Q, part 5 and 6$)^{23}$ was employed to retrospectively elicit information on physical abuse by the main mother and father figures (usually, but not necessarily, the biological parents), sexual abuse by any adult or an individual at least 5 years older than the recipient all prior to 17 years of age. The CECA.Q was read out to all participants during faceto-face interviews to improve the accuracy of the fixed category responses obtained. ${ }^{24}$ Sexual abuse was defined as inappropriate touching, genital contact, erection and ejaculation, rape, and a refusal by the participant to provide further information after having acknowledged an incident of abuse. Reported incidents of physical abuse were coded as moderate when injuries did not require medical intervention and severe when they did. Moderate sexual abuse was defined as 
inappropriate touching, a refusal by the participant to provide further information after having acknowledged an incident of abuse, and severe sexual abuse as genital contact, erection and ejaculation, or rape. Before the study, the questionnaire was translated and back translated. Basic psychometric properties of the Czech version were validated with satisfactory results (Cronbach's $\alpha$ 0.522, inter-item correlation 0.212).

\section{Ethics approval}

The study was approved by the Ethics Committee of the First Faculty of Medicine, Charles University in Prague. All individuals approached to participate in the study were given verbal and written details of the study and those who agreed signed consents to participate. The participants with psychotic disorders provided verbal permission for collaterals to report on their behavior.

\section{Statistical analyses}

Analyses were conducted in several consecutive steps. First, the characteristics of participants with and without a psychotic disorder were compared within sex using chisquared tests and ANOVAs. Second, pairwise correlations of assaultiveness in past 6 months with a set of hypothesized risk/protective factors were tested using unadjusted ORs as a statistical measure of association (univariate analysis). The hypothesized factors included sociodemographic characteristics of participants (age, sex, level of education, marital status, and employment status), childhood maltreatment (physical and/or sexual abuse), level of substance use (alcohol, illicit drugs), presence of PTSD, and recent physical victimization. The pairwise associations were tested separately for each group of participants (group with a psychotic disorder vs comparison group) and for the total matched data set. Third, multiple logistic regression models were conducted to identify factors that were independently associated with committing an assault (multivariate analysis).

Two series of logistic regressions were conducted within the multivariate analysis - first within the group of participants with a psychotic disorder and second within those from the comparison group. In each of the series, seven logistic regression models were constructed. In models 1 through 6 , factors that were correlated with assaults in the previous univariate analysis at $P \leq 0.1$ probability level were included, as recommended elsewhere. ${ }^{25,26}$ Final model 7 included those factors that were proved to be significant independent predictors of assaults in the six preceding regression models conducted within the given series. In all of the multivariate models, participant's age and gender were used as controlling variables.
Within both univariate and multivariate analyses, a nonparametric approach to statistical inference based on bootstrapping was applied. Bootstrapping was used in order to provide more accurate $95 \%$ CI for parameter estimates, as well as to account for a possible type I error, which can occur within multiple hypotheses testing. This approach is recommended particularly when the sample size is relatively small, or the data are not well behaved. ${ }^{27}$ In both univariate and multivariate analyses, bootstrapping of 100 replications with replacement was used.

In multivariate analysis, independent effects of the ageand gender-adjusted risk/protective factors included in logistic regression models (models 1 through 7 within the given series) were additionally tested by the partial likelihood ratio test (partial LR test). The effects of independent variables on assaults were checked for collinearity through an examination of the variance inflation factor (VIF) as well. Comprehensive model descriptive statistics were provided for each regression model as recommended for logistic regression. . $5,26,28$

All analytical procedures were conducted by using the Stata 15.1 statistical software package. ${ }^{29}$

\section{Results}

\section{Characteristics of participants}

The final sample included matched pairs of 93 men and 65 women. All participants were white. The men with psychosis had been currently hospitalized, on average, for 34.6 days $(\mathrm{SD}=14.8)$ and the women with psychosis for 38.2 days $(\mathrm{SD}=14.5)$. Among those with psychosis, hazardous drinking was identified among 15 (16.1\%) men and seven (10.8\%) women; no harmful drinking was identified; problem drinking, confirmed by MINI Interview as dependence, was diagnosed among two (2.2\%) men and two (3.1\%) women; none presented with Antisocial Personality Disorder (ASPD).

In those without psychosis, seven (7.5\%) men and five (9.2\%) women met criteria for a mood disorder; five (5.4\%) men and five (7.7\%) women for anxiety disorder; six (6.5\%) men and none of women for ASPD; 34 (36.6\%) men and eight (12.3\%) women for hazardous drinking, four (4.3\%) men and no women for harmful drinking and five (5.4\%) men and two (3.1\%) women were diagnosed for alcohol dependence, $16(17.2 \%)$ men and ten (15.4\%) women for harmful illicit drug abuse, and illicit drug dependence in one (1.1\%) men.

As presented in Table 1, those with and without psychosis were of similar age and levels of education, while fewer of those with psychosis had been employed at the time of hospitalization. The men with psychosis were similar to those without as to the prevalence of recent victimization, childhood maltreatment, and the level of drug use, but 


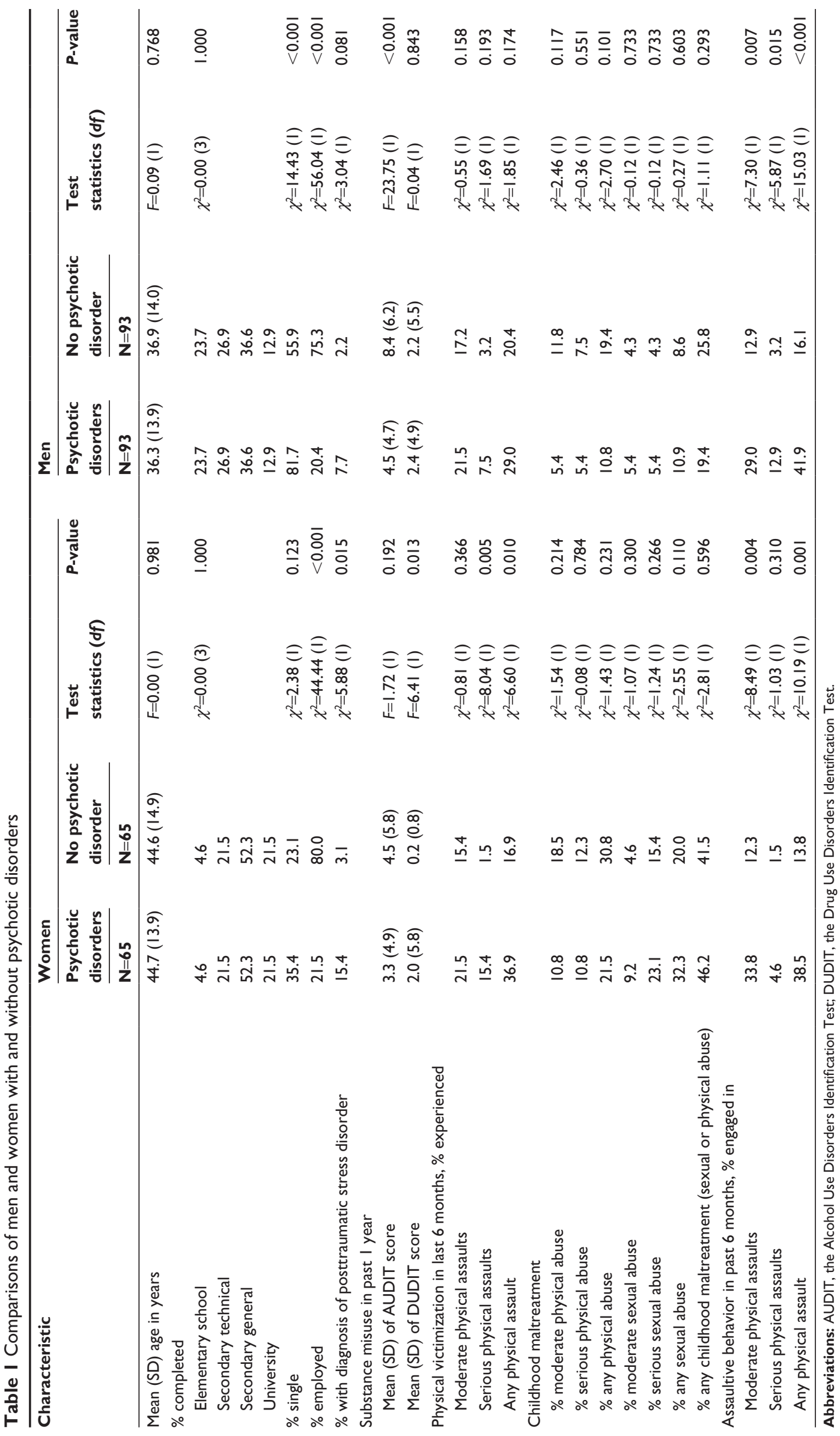


fewer of the men with psychosis presented with alcohol abuse. Among the women, more of those with than without psychosis presented with PTSD and had recently been the victim of an assault. Six women with $(9.2 \%)$ and one woman without psychosis $(1.5 \%)$ reported being sexually abused in the previous 6 months.

Among the men, committing any assault was reported by $41.9 \%$ of those with psychosis and $16.1 \%$ of those without psychosis. Thus, the men with psychotic disorders were almost four times more likely to commit an assault than those without $(\mathrm{OR}=3.76,95 \% \mathrm{CI}=1.89-7.48, P<0.001$ ). Similarly, women with psychosis were more likely than those without it to have committed assaults: any assault $38.5 \%$ vs $13.8 \%$. Thus, women with psychotic disorders were almost four times more likely to commit assaults than those without psychosis $(\mathrm{OR}=3.89,95 \% \mathrm{CI}=1.64-9.22, P=0.002)$.

\section{Univariate analysis of factors associated with assaults}

Table 2 presents pairwise associations of assaults with selected factors, estimated by unadjusted ORs. The associations are presented both separately by group of participants (with vs without a psychotic disorder) and for the total matched sample; the bootstrapped $95 \%$ CIs are also presented. The selected factors included sociodemographic characteristics of participants, substance use, recent physical victimization, presence of PTSD, and history of childhood maltreatment. Finally, the presence of a psychotic disorder was examined as a factor within the total sample.

As presented in Table 2, there were significant pairwise associations of assaults with decreasing age, history of childhood maltreatment, higher levels of alcohol and illicit drug score, and recent physical victimization. These factors were found to be significantly correlated with assaults (probability level $\leq 5 \%$ ) within the group of participants with a psychotic disorder as well as within the comparison group, except the illicit drug score among those with psychosis, which was associated with assaults at a marginal $P<0.1$ probability level. The associations of assaults were significant neither with gender nor with education of participants.

Among the group of participants with a psychotic disorder, employment was found to be negatively associated with assaultiveness. Marital status (ever married) was associated with fewer assaults only among participants from the comparison group. As there were no cases of assaultive behavior among participants diagnosed with PTSD from the comparison group, the association of assaults with PTSD was examined only within the group with a psychotic disorder; however, no significant effect was detected. Within the total sample, the presence of a psychotic disorder increased the risk of assaultiveness almost four-fold.

\section{Multivariate analysis of factors associated with assaults among persons with psychosis}

Table 3 presents adjusted ORs as derived from the multiple logistic regression models conducted within the participants with a psychotic disorder. The bootstrapped 95\% CIs and model fit statistics for each logistic regression are presented as well. All the models included participants' age and gender as controlling variables.

In Model 1, the significance of employment as an independent protective factor against assaultiveness was

Table 2 Unadjusted ORs of assaultive behavior for selected factors, by group of participants, bootstrapped ${ }^{\mathrm{a}}$ results

\begin{tabular}{|c|c|c|c|c|c|c|c|c|c|}
\hline \multirow[t]{3}{*}{ Factor } & \multicolumn{6}{|c|}{ Group of participants } & \multirow{2}{*}{\multicolumn{3}{|c|}{ Total matched sample }} \\
\hline & \multicolumn{3}{|c|}{ With a psychotic disorder } & \multicolumn{3}{|c|}{ No psychotic disorder } & & & \\
\hline & OR & $(95 \% \mathrm{Cl})^{\mathrm{b}}$ & $P$-value & OR & $(95 \% \mathrm{Cl})^{\mathrm{b}}$ & $P$-value & OR & $(95 \% \mathrm{Cl})^{\mathrm{b}}$ & $P$-value \\
\hline Age & $0.97 * * *$ & $(0.942-0.990)$ & 0.006 & $0.93^{* * *}$ & $(0.900-0.969)$ & $<0.001$ & $0.96 * * *$ & $(0.942-0.978)$ & $<0.001$ \\
\hline Male sex & 1.16 & $(0.613-2.177)$ & 0.655 & 1.20 & $(0.491-2.919)$ & 0.693 & 1.16 & $(0.705-1.893)$ & 0.567 \\
\hline Education (lower than university) & 1.66 & $(0.599-4.590)$ & 0.331 & 2.40 & $(0.673-8.556)$ & 0.177 & 1.77 & $(0.758-4.092)$ & 0.188 \\
\hline Marital status (ever married) & 0.64 & $(0.331-1.242)$ & 0.188 & $0.19 * * *$ & $(0.062-0.591)$ & 0.004 & $0.35 * * *$ & $(0.200-0.620)$ & $<0.00 \mathrm{I}$ \\
\hline Employed & $0.39 * *$ & $(0.167-0.931)$ & 0.034 & 0.67 & $(0.205-2.192)$ & 0.509 & $0.30 * * *$ & $(0.166-0.540)$ & $<0.00$ I \\
\hline Childhood maltreatment & $3.27 * * *$ & $(1.670-6.405)$ & 0.001 & $4.54^{* * *}$ & $(1.602-12.85)$ & 0.004 & $3.15^{* * * *}$ & $(I .877-5.27 I)$ & $<0.00$ I \\
\hline AUDIT & $1.09 * *$ & $(1.006-1.174)$ & 0.034 & $1.08^{* *}$ & $(1.006-1.159)$ & 0.034 & $1.04 *$ & $(1.000-1.084)$ & 0.052 \\
\hline DUDIT & $1.07 *$ & $(0.996-1.138)$ & 0.065 & $1.27^{* * *}$ & $(1.139-1.419)$ & $<0.001$ & $1.13 * * *$ & $(1.063-1.197)$ & $<0.00$ I \\
\hline Posttraumatic stress disorder & 0.43 & $(0.128-1.442)$ & 0.171 & NA & - & - & 0.61 & $(0.175-2.098)$ & 0.429 \\
\hline Physical victimization & $5.13 * * *$ & $(2.409-10.94)$ & $<0.001$ & $10.3^{* * *}$ & $(3.737-28.52)$ & $<0.001$ & $7.09 * * *$ & $(3.922-12.819)$ & $<0.00 \mathrm{I}$ \\
\hline Psychotic disorder & - & - & - & - & - & - & $3.80 * * *$ & $(2.060-7.014)$ & $<0.00 \mathrm{I}$ \\
\hline Number of participants & \multicolumn{3}{|c|}{158} & \multicolumn{3}{|c|}{158} & \multicolumn{3}{|c|}{316} \\
\hline
\end{tabular}

Notes: a Number of bootstrap replications $=100$; ${ }^{b}$ Normal based $95 \% \mathrm{Cl}$; NA represents not applicable. $* P<0.1 ; * * P<0.05 ; * * * P<0.01$.

Abbreviations: AUDIT, the Alcohol Use Disorders Identification Test; DUDIT, the Drug Use Disorders Identification Test. 


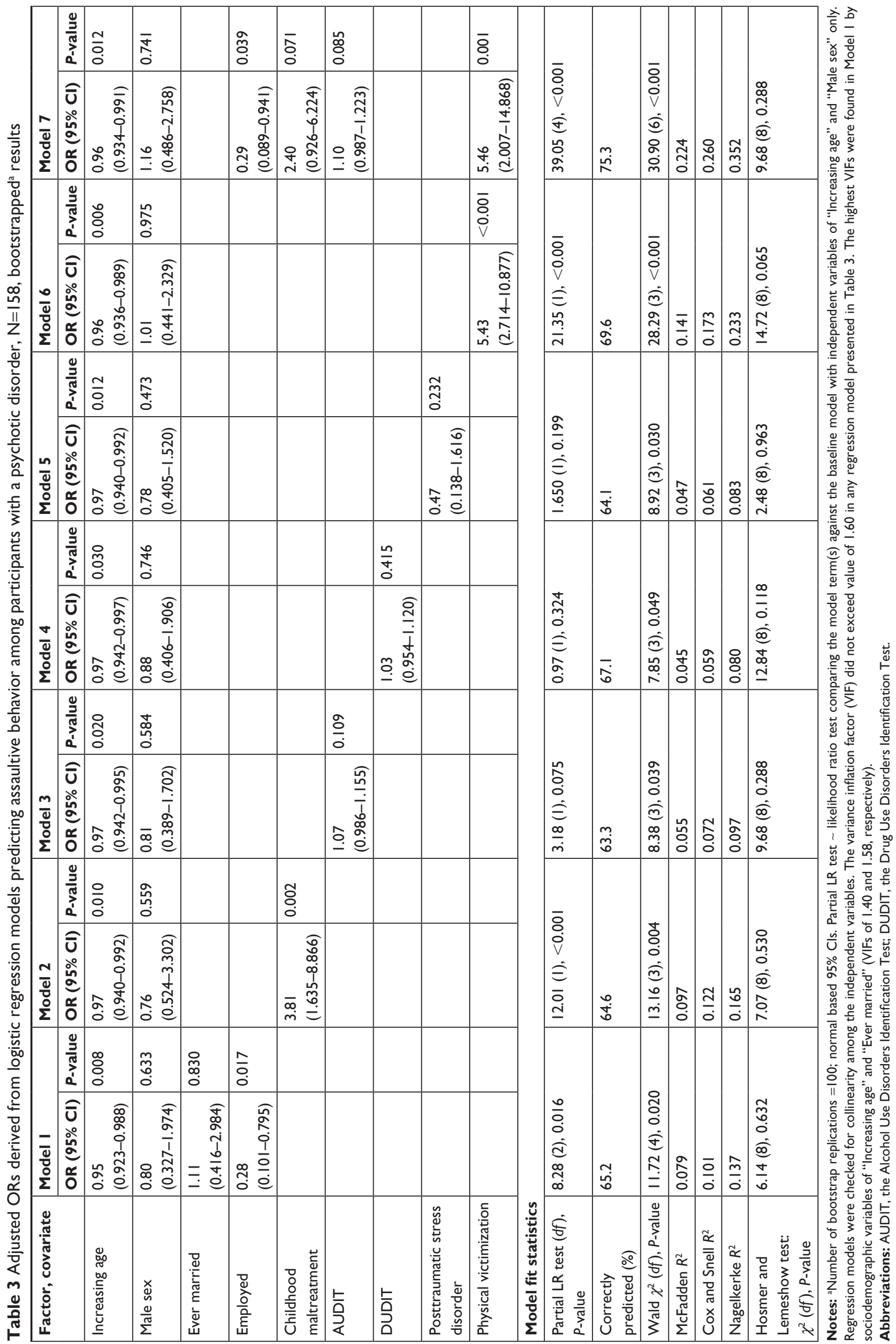


confirmed. The effect of marital status was not significant after adjustment to other sociodemographic covariates in Model 1. In Model 2, the childhood maltreatment significantly increased the risk of assaultiveness almost four times. In Model 3, the level of alcohol use was associated with assaults at marginal $P<0.1$ probability level (partial LR test: $3.18[d f=1], P=0.075)$. After adjustment for age and gender, illicit drug use and PTSD in Models 4 and 5 were not significant predictors within the group of participants with a psychotic disorder. In Model 6, recent physical victimization was associated with more than five times higher odds of assaultiveness as compared to participants without the victimizing experience.

The final Model 7 included the predictors considered as significant in preceding models, that is, fully adjusted effects of employment, childhood maltreatment, level of alcohol use, and recent physical victimization are presented here (adjusted for age and gender as well). Employment and recent physical victimization were found to be independently associated with assaults at $P<0.05$ level, childhood maltreatment and alcohol use score at marginal $P<0.1$ level.

As presented by model fit statistics, regression models explained considerable portion of variability of the data ( $R^{2}$ statistics from 0.224 to 0.352 in the final model) with a statistically good model fit (as indicated by Hosmer and Lemeshow test, all the $P$-values $>0.05$ ). In the final model, presence of assaultive behavior was correctly predicted by $75.3 \%$ of participants.

\section{Multivariate analysis of factors associated with assaults in the matched comparison group}

Table 4 presents outputs of multiple logistic regression models conducted in the matched group of participants without a psychotic disorder. All the regression models included participant's age and gender as controlling variables.

In Model 1, adjusted ORs for employment were significant at marginal $P<0.1$ level. However, the partial LR test ( $7.33[d f=2], P=0.026)$ indicated the importance of at least one of the sociodemographic terms included in Model 1 (employment; marital status). In Models 2 through 4, the significant independent risk effects of childhood maltreatment, level of alcohol use, level of illicit drug use, and recent physical victimization on assaultiveness were confirmed. The effect of PTSD could not be estimated within participants from the comparison group. In Model 6, the presence of recent physical victimization increased the odds of assaultiveness almost seven-fold.
In the final Model 7, independent effects of the factors confirmed in preceding six models were tested simultaneously, except for marital status and PTSD. Here, significant $(P<0.05)$ fully adjusted effects of childhood maltreatment and physical victimization were confirmed. As regards to the effects of alcohol use and illicit drug use on assaults in Model 7, these two factors were found to be intercorrelated (Pearson $r=0.39, P<0.001)$. Given both the correlation between the variables and limited regressor space in the data $(\mathrm{N}=158)$, the estimated ORs on assaults were considered as overadjusted. Fully adjusted ORs for employment were not significant after controlling for the rest of predictors included in Model 7.

Similarly to the previous group of participants, regression models conducted within the comparison group explained considerable portion of variability of the data $\left(R^{2}\right.$ statistics from 0.318 to 0.554 in the final model) with a statistically good model fit. The final model correctly predicted assaultive behavior by $90.5 \%$ of participants without psychosis.

\section{Assaultive behavior and active psychotic symptoms}

Among the 93 men with psychosis, a self- or collateral-report indicated that during the 6 months preceding the current admission, 39 (41.9\%) had committed any assault and $30(76.9 \%)$ of these 39 men experienced positive psychotic symptoms at the time of the assault. Among the 65 women, $25(38.5 \%)$ had committed any assault, and eleven (44\%) of these 25 assaultive women experienced positive psychotic symptoms at the time of the assault.

\section{Discussion}

In our sample recruited in the Czech Republic, men and women with psychosis were approximately four times more likely to commit an assault than non-psychotic controls matched for age, gender, and education. This result is consistent with previous findings. ${ }^{1-3,30}$

Strongest risk factors for violence in persons with and without psychosis were recent physical victimization, childhood maltreatment, the level of drug use, and the level of alcohol use. Increasing age and employment were protective factors. Except for drug use, which appeared to have greater effect on violence in the group without psychosis, there were no major differences between patients and controls in these risk and protective factors.

In our study, patients' and collaterals' reports of assaults and victimization were largely consistent and support evidence that self-reports of victimization by individuals with severe mental illness are valid. ${ }^{31-33}$ Nevertheless, some data 


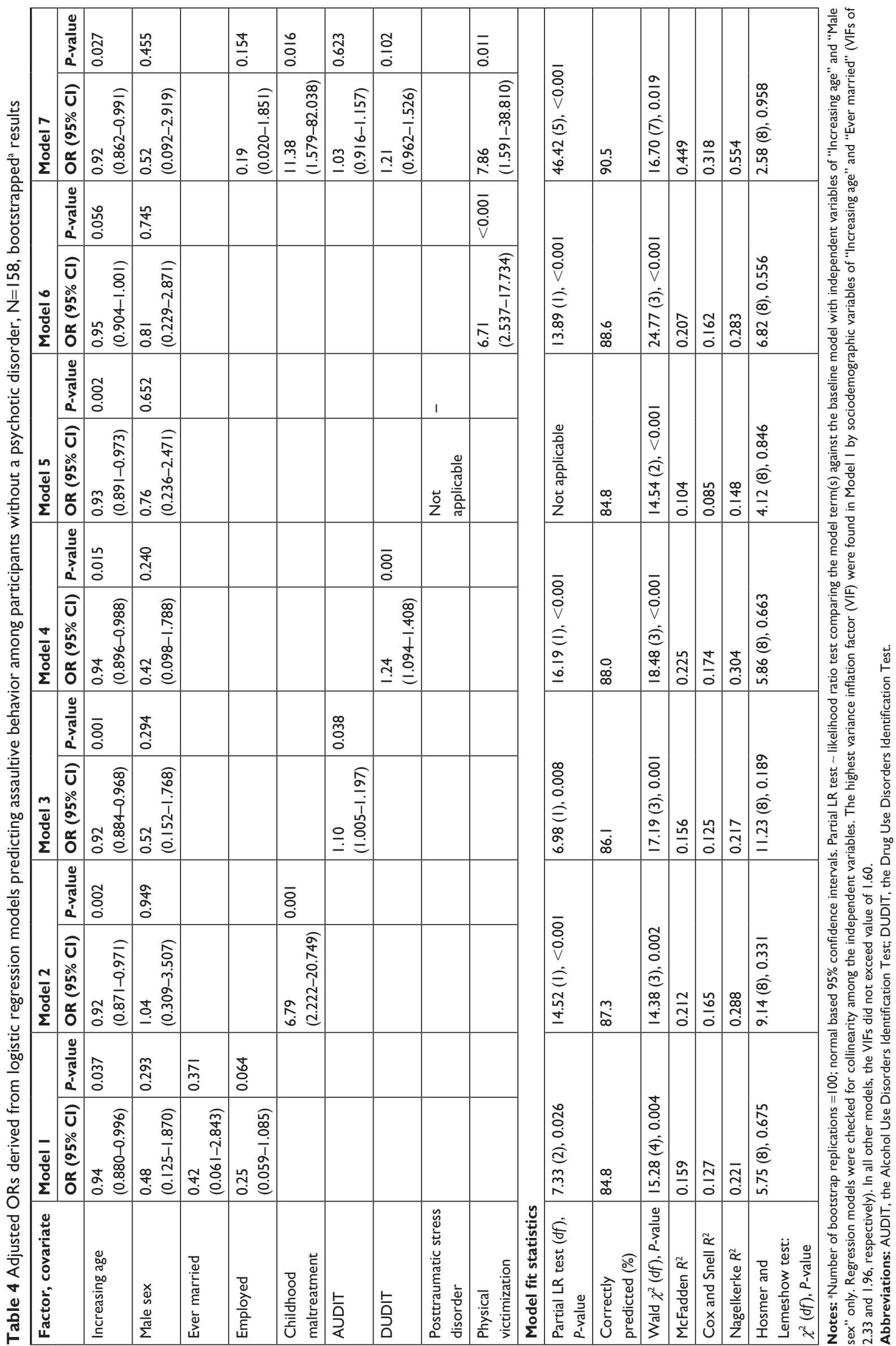


suggest that self-reports of violence by persons with severe mental illness may not be valid. ${ }^{34}$

\section{Victimization}

Persons with psychosis were about two times more likely to be victims of a physical violence than non-psychotic controls, particularly among women participants (prevalence of any physical victimization among women was $36.9 \%$ as compared to $\left.16.6 \% ; \chi^{2}=6.60(1), P=0.010\right)$.

In the final regression model, recent victimization raised the risk of violent behavior more than five times among participants with a psychotic disorder and almost eight times among those from the comparison group. This increase is consistent with the results of recent studies conducted within the mentally ill ${ }^{8-10}$ as well as with the recent Swedish registry study of triggers of violence in patients with schizophrenia, bipolar disorder, and unaffected controls. ${ }^{35}$ Among six potential triggering events tested, violent victimization was most likely to trigger violent behavior.

Additional statistically significant risk factor in the final model of the matched comparison group was childhood maltreatment. Childhood maltreatment is known to be associated with violence in adulthood. ${ }^{36}$ Universal programs and laws are in place to prevent it, but results of the present project suggest that these policies are not entirely effective. In our study, the effect of childhood maltreatment was significant after adjustment to age and gender, but after further adjusting for employment, level of alcohol use, and recent physical victimization, the significance is marginal $(\mathrm{OR}=2.4,95 \%$ $\mathrm{CI}=0.926-6.224, P<0.1)$. However, this marginal significance is consistent with recent review, suggesting that individuals with psychosis who had been victims of maltreatment in childhood were approximately twice as likely to be violent as individuals with psychosis who had not been victims. ${ }^{37}$ These results confirm the role of victimization, both recent and past, in aggressive behavior of persons with psychosis.

\section{Substance abuse}

Alcohol has been linked to violence in literature going back for decades, ${ }^{7}$ and its effect on violence has been confirmed in large epidemiological studies as well. ${ }^{38}$ We found lower alcohol use in those with psychosis than in the comparison group. Furthermore, our study estimates alcohol use score in those with psychosis as a rather marginally significant predictor for assaultive behavior (adj. $\mathrm{OR}=1.07, P=0.109$ ). Among the nonpsychotic controls, the effect of alcohol use score on assaultive behavior was statistically significant, but very similar in size to the effect in psychotics (adj. OR $=1.10, P=0.038$ ).
Similar to the Czech general population, the prevalence of hazardous drinking in our comparison group is high. The Czech Republic has one of the world's highest rates of alcohol consumption. ${ }^{39,40}$ We hypothesized that higher alcohol consumption in comparison group is associated with increased level of substance abuse in acute stomatologic patients and has a direct impact of alcohol toxicity on dental health. ${ }^{41-43}$ Contrary to most findings in the literature, ${ }^{7}$ the prevalence of hazardous drinking was higher in comparison group than in patients with psychosis. However, this finding is in line with our previous study of schizophrenia patients, which showed relatively low prevalence of substance misuse. ${ }^{44}$ We had hypothesized ${ }^{44}$ that the relatively low rates of substance misuse were associated with long periods of hospitalization, good access to care, universal health insurance, and a high level of supervision of such patients.

\section{Psychotic symptoms}

In our sample, $64.1 \%$ of the individuals with psychosis reported experiencing positive symptoms coincidental with their assaults, with the remaining $35.9 \%$ perhaps linked to risk factors that may occur in healthy people. On the other hand, an intensive study of psychotic inpatients selected for assaultiveness estimated the proportion of assaults attributable to psychotic symptoms at $20 \% .{ }^{45}$ Different patients and different methods were used in these two studies, which may partly explain the disparate results. In any event, high levels of positive symptoms have been shown to be strongly and uniquely associated with assaultiveness. ${ }^{46}$

Persons with psychosis may lack skills to resolve interpersonal conflicts and consequently resort to physical violence that in turn increases the likelihood that they themselves will be victimized. Future studies could test whether social-skills training leads to a reduction in victimization experiences.

\section{Protective factors}

As regards sociodemographic variables, two significant protective factors have been identified in the participants with a psychotic disorder: older age and being employed. Violent behavior is well known to decrease from adolescence through the middle age. Regarding employment, there is some evidence that giving people a job reduces their violence. ${ }^{47}$ Our data support the importance of sheltered employment for persons with psychotic disorder. On the other hand, the observed negative relationship between employment and aggression might be due to the fact that aggressive people have difficulties keeping a job. 


\section{Implications}

The results have implications for the assessment of the risk of violence among patients with psychosis and for treatment. The Historical, Clinical, Risk Management-20 (HCR-20) (8 $^{48}$ has been validated and is used in many countries ${ }^{49}$ However, HCR- $20^{\mathrm{V} 3}$ may underestimate the importance of recent victimization in assessing the risk of violence among psychotic patients.

The results of the present study illustrate the importance of conducting studies of violence and its correlates among persons with psychotic disorders in different countries and cultures. While many studies from the US, UK, and Scandinavia have shown that substance misuse is strongly associated with violence in this population, the association was weaker in the present study. This finding confirms a previous study in the Czech Republic. ${ }^{44,50}$ This study might contribute to current research discussion and appeal to determine more fully why some people with mental illnesses are especially vulnerable to being subjected to crime. $^{51}$

\section{Strengths and limitations}

The study has a number of strengths. It included persons with and without psychosis living in the same city and matched for gender, age, and education. The matched comparison group of persons without psychosis is a major strength of this study. It enabled a direct comparison of the risk factors of assaultive behavior between persons with and without psychosis. Established diagnostic criteria (ICD-10) and instruments (such as the MINI and the MacArthur interview) were used throughout.

The study adds data on risk factors for violence that are derived from a homogeneous population and a different culture than the typical published reports on this topic. Therefore, it can contribute to current research discussion.

The principal limitation of the study is its relatively small sample size. This made it necessary to treat assaults and several other variables as dichotomous indicators rather than examining different levels of severity (the cell counts would be too small for such analyses to be meaningful). Furthermore, it would have been very useful to have a measure of psychopathy in patients and controls. It is quite possible that risk factors for violence vary with the perpetrator's personality and with the type of assault. Finally, alcohol users might be overrepresented among the comparison group and thus the influence of alcohol use as a risk factor for violence and victimization may have been overestimated. These are questions for future research.

\section{Conclusion}

Persons with psychosis were almost four times more likely to commit assaults than those without it. Recent physical victimization, history of childhood maltreatment, and the level of alcohol use were associated with an increased risk of assaultiveness. Higher age and being employed appeared to act as protective factors against violence. Most physical assaults by patients with psychosis were committed when they were experiencing positive psychotic symptoms. The risk factors among participants with and without psychosis were largely similar. Commonly used risk prediction instruments may underestimate the risk of violence as they take insufficient account of current victimization. Treatment programs and living arrangements teaching social skills to avoid victimization and substance misuse could contribute to reducing assaults by patients with psychosis.

\section{Acknowledgments}

This work was supported by The Ministry of Education, Youth and Sports of the Czech Republic (grant number Progres Q06/LF1 and SVV 260367), The Ministry of Health of the Czech Republic, Czech Health Research Council (grant number AZV 17-32445A), and Charles University Research Center program No 9.

\section{Author contributions}

All authors contributed toward data analysis, drafting and critically revising the paper, gave final approval of the version to be published, and agree to be accountable for all aspects of the work.

\section{Disclosure}

The authors report no conflicts of interest in this work.

\section{References}

1. Hodgins S, Alderton J, Cree A, Aboud A, Mak T. Aggressive behaviour, victimization and crime among severely mentally ill patients requiring hospitalisation. Br J Psychiatry. 2007;191:343-350.

2. Fazel S, Långström N, Hjern A, Grann M, Lichtenstein P, Schizophrenia LP Schizophrenia, substance abuse, and violent crime. JAMA. 2009;301(19): 2016-2023

3. Witt K, van Dorn R, Fazel S. Risk factors for violence in psychosis: systematic review and meta-regression analysis of 110 studies. PLoS One. 2013;8(2):e55942.

4. Fazel S, Chang Z, Fanshawe T, et al. Prediction of violent reoffending on release from prison: derivation and external validation of a scalable tool. Lancet Psychiatry. 2016;3(6):535-543.

5. Hodgins S. Violent behaviour among people with schizophrenia: a framework for investigations of causes, and effective treatment, and prevention. Philos Trans $R$ Soc Lond B Biol Sci. 2008;363(1503): 2505-2518

6. Honkonen T, Henriksson M, Koivisto AM, Stengård E, Salokangas RK Violent victimization in schizophrenia. Soc Psychiatry Psychiatr Epidemiol. 2004;39(8):606-612. 
7. Volavka J. Neurobiology of Violence. 2nd ed. Washington, DC: American Psychiatric Publishing; 2002.

8. Sadeh N, Binder RL, Mcniel DE. Recent victimization increases risk for violence in justice-involved persons with mental illness. Law Hum Behav. 2014;38(2):119-125.

9. Johnson KL, Desmarais SL, Grimm KJ, Tueller SJ, Swartz MS, van Dorn RA. Proximal risk factors for short-term community violence among adults with mental illnesses. Psychiatr Serv. 2016;67(7): 771-778.

10. Short TB, Thomas S, Luebbers S, Mullen P, Ogloff JR. A case-linkage study of crime victimisation in schizophrenia-spectrum disorders over a period of deinstitutionalisation. BMC Psychiatry. 2013;13:66.

11. Latalova K, Kamaradova D, Prasko J. Violent victimization of adult patients with severe mental illness: a systematic review. Neuropsychiatr Dis Treat. 2014;10:1925-1939.

12. Dean K, Laursen TM, Pedersen CB, Webb RT, Mortensen PB, Agerbo E. Risk of being subjected to crime, including violent crime, after onset of mental illness: A Danish national registry study using police data. JAMA Psychiatry. 2018;75(7):689-696.

13. Buckley PF, Miller BJ, Lehrer DS, Castle DJ. Psychiatric comorbidities and schizophrenia. Schizophr Bull. 2009;35(2):383-402.

14. Newman JM, Turnbull A, Berman BA, Rodrigues S, Serper MR. Impact of traumatic and violent victimization experiences in individuals with schizophrenia and schizoaffective disorder. J Nerv Ment Dis. 2010;198(10):708-714.

15. Sheehan DV, Lecrubier Y, Sheehan KH, et al. The Mini-International Neuropsychiatric Interview (M.I.N.I.): the development and validation of a structured diagnostic psychiatric interview for DSM-IV and ICD-10. J Clin Psychiatry. 1998;59(Suppl 20):34-57.

16. Preiss $\mathrm{M}, \mathrm{Mohr} \mathrm{P}$, Kopeček $\mathrm{M}$, et al. Trauma a stres osm měsíců po povodních v roce 2002 [Trauma and stress eight months after floods in 2002]. Psychiatrie. 2004;(3):180-186. Czech.

17. First M, Spitzer R, Gibbon M, Williams J. Structured Clinical Interview for the DSM-IV Axis I Disorders (SCID-I), Clinical Version. Washington, DC: American Psychiatric Association; 1996.

18. Saunders JB, Aasland OG, Babor TF, de La Fuente JR, Grant M. Development of the Alcohol Use Disorders Identification Test (AUDIT): WHO Collaborative Project on Early Detection of Persons with Harmful Alcohol Consumption - II. Addiction. 1993;88(6):791-804.

19. Berman AH, Bergman H, Palmstierna T, Schlyter F. Evaluation of the Drug Use Disorders Identification Test (DUDIT) in criminal justice and detoxification settings and in a Swedish population sample. Eur Addict Res. 2005;11(1):22-31.

20. Sovinová H, Csémy L. The Czech audit: internal consistency, latent structure and identification of risky alcohol consumption. Cent Eur J Public Health. 2010;18(3):127-131.

21. Steadman HJ, Mulvey EP, Monahan J, et al. Violence by people discharged from acute psychiatric inpatient facilities and by others in the same neighborhoods. Arch Gen Psychiatry. 1998;55(5):393-401.

22. Swanson JW, Swartz MS, van Dorn RA, et al. A national study of violent behavior in persons with schizophrenia. Arch Gen Psychiatry. 2006; 63(5):490-499.

23. Bifulco A, Bernazzani O, Moran PM, Jacobs C. The childhood experience of care and abuse questionnaire (CECA.Q): validation in a community series. Br J Clin Psychol. 2005;44(Pt 4):563-581.

24. Trotta A, Iyegbe $C$, di Forti M, et al. Interplay between schizophrenia polygenic risk score and childhood adversity in first-presentation psychotic disorder: a pilot study. PLoS One. 2016;11(9):e0163319.

25. Agresti A. An Introduction to Categorical Data Analysis. Hoboken, NJ: John Wiley \& Sons, Inc; 2007.

26. Hosmer DW, Lemeshow S. Applied Logistic Regression: Hoboken, NJ: John Wiley \& Sons, Inc; 2004.

27. Fox J. Applied Regression Analysis and Generalized Linear Models: Thousand Oaks, CA: SAGE Publications Inc; 2008.

28. Bender R, Grouven U. Logistic regression models used in medical research are poorly presented. $B M J .1996 ; 313(7057): 628$.
29. StataCorp. Stata Statistical Software: Release 15. College Station, TX: StataCorp LLC [computer program]; 2017.

30. van Dorn R, Volavka J, Johnson N. Mental disorder and violence: is there a relationship beyond substance use? Soc Psychiatry Psychiatr Epidemiol. 2012;47(3):487-503.

31. Fisher HL, Craig TK, Fearon P, et al. Reliability and comparability of psychosis patients' retrospective reports of childhood abuse. Schizophr Bull. 2011;37(3):546-553.

32. Goodman LA, Thompson KM, Weinfurt K, et al. Reliability of reports of violent victimization and posttraumatic stress disorder among men and women with serious mental illness. J Trauma Stress. 1999;12(4):587-599.

33. Teplin LA, Mcclelland GM, Abram KM, Weiner DA. Crime victimization in adults with severe mental illness: comparison with the National Crime Victimization Survey. Arch Gen Psychiatry. 2005; 62(8):911-921.

34. Pettit B, Greenhead S, Khalifeh H, Drennan V, Hart T, Hogg J. At Risk yet dismissed: the criminal victimisation of people with mental health problems. Victim Support. 2013. Available from: https://www. victimsupport.org.uk/sites/default/files/At $\% 20$ risk $\% 2 \mathrm{C} \% 20$ yet $\% 20$ dismissed\%20-\%20full\%20report.pdf. Accessed October 01, 2018.

35. Sariaslan A, Lichtenstein P, Larsson H, Fazel S. Triggers for violent criminality in patients with psychotic disorders. JAMA Psychiatry. 2016;73(8):796-803.

36. Harford TC, Yi HY, Grant BF. Associations between childhood abuse and interpersonal aggression and suicide attempt among U.S. adults in a national study. Child Abuse Negl. 2014;38(8):1389-1398.

37. Green K, Browne K, Chou S. The relationship between childhood maltreatment and violence to others in individuals with psychosis: a systematic review and meta-analysis. Trauma Violence Abuse. Epub 2017 Jan 1.

38. Pulay AJ, Dawson DA, Hasin DS, et al. Violent behavior and DSM-IV psychiatric disorders: results from the national epidemiologic survey on alcohol and related conditions. J Clin Psychiatry. 2008;69(1):12-22.

39. Global Alcohol Report. Czech Republic; 2014. Available from: http:// www.who.int/substance_abuse/publications/global_alcohol_report/ profiles/cze.pdf. Accessed December 10, 2014.

40. Mladovsky P, Allin S, Masseria C, Hernández-Quevedo C, Mcdaid D, Mossialos E. Health in the European Union. Trends and Analysis. World Health Organization; 2009. Available from: http://www.euro. who.int/_data/assets/pdf_file/0003/98391/E93348.pdf. Accessed October 01, 2018.

41. Petti S, Scully C. Oral cancer: the association between nation-based alcohol-drinking profiles and oral cancer mortality. Oral Oncol. 2005;41(8): 828-834.

42. D'Amore MM, Cheng DM, Kressin NR, et al. Oral health of substancedependent individuals: impact of specific substances. J Subst Abuse Treat. 2011;41(2):179-185.

43. Amaral CS, da Silva-Boghossian CM, Leão AT, Colombo AP. Evaluation of the subgingival microbiota of alcoholic and non-alcoholic individuals. J Dent. 2011;39(11):729-738.

44. Vevera J, Hubbard A, Veselý A, Papezová H. Violent behaviour in schizophrenia. Retrospective study of four independent samples from Prague, 1949 to 2000. Br J Psychiatry. 2005;187:426-430.

45. Nolan KA, Czobor P, Roy BB, et al. Characteristics of assaultive behavior among psychiatric inpatients. Psychiatr Serv. 2003;54(7):1012-1016.

46. Hodgins S, Riaz M. Violence and phases of illness: differential risk and predictors. Eur Psychiatry. 2011;26(8):518-524.

47. Heller SB. Summer jobs reduce violence among disadvantaged youth. Science. 2014;346(6214):1219-1223.

48. Douglas KS, Hart SD, Webster CD, Belfrage H, Guy LS, Wilson CM. Historical-Clinical-Risk Management-20, Version 3 (HCR-20V3): development and overview. Int J Forensic Ment Health. 2014;13(2):93-108.

49. O'Shea LE, Picchioni MM, Mason FL, Sugarman PA, Dickens GL. Differential predictive validity of the Historical, Clinical and Risk Management Scales (HCR-20) for inpatient aggression. Psychiatry Res. 2014;220(1-2):669-678. 
50. Vevera J, Brazinova A, Nemec J, Palova E, Raboch J. Human resources and training. In: Scheffler R, Potucek M, editors. Mental Health Care Reform in the Czech and Slovak Republics, 1989 to the Present. Prague: Karolinum Press; 2008:197-223.
51. Swanson JW, Belden CM. The link between mental illness and being subjected to crime in Denmark vs the United States: how much do poverty and the safety net matter? JAMA Psychiatry. 2018;75(7): 669-670.

\section{Publish your work in this journal}

Neuropsychiatric Disease and Treatment is an international, peerreviewed journal of clinical therapeutics and pharmacology focusing on concise rapid reporting of clinical or pre-clinical studies on a range of neuropsychiatric and neurological disorders. This journa is indexed on PubMed Central, the 'PsycINFO' database and CAS, and is the official journal of The International Neuropsychiatric Association (INA). The manuscript management system is completely online and includes a very quick and fair peer-review system, which is all easy to use. Visit http://www.dovepress.com/testimonials.php to read real quotes from published authors.

\footnotetext{
Submit your manuscript here: http://www.dovepress.com/neuropsychiatric-disease-and-treatment-journal
} 